\title{
Conference photo
}

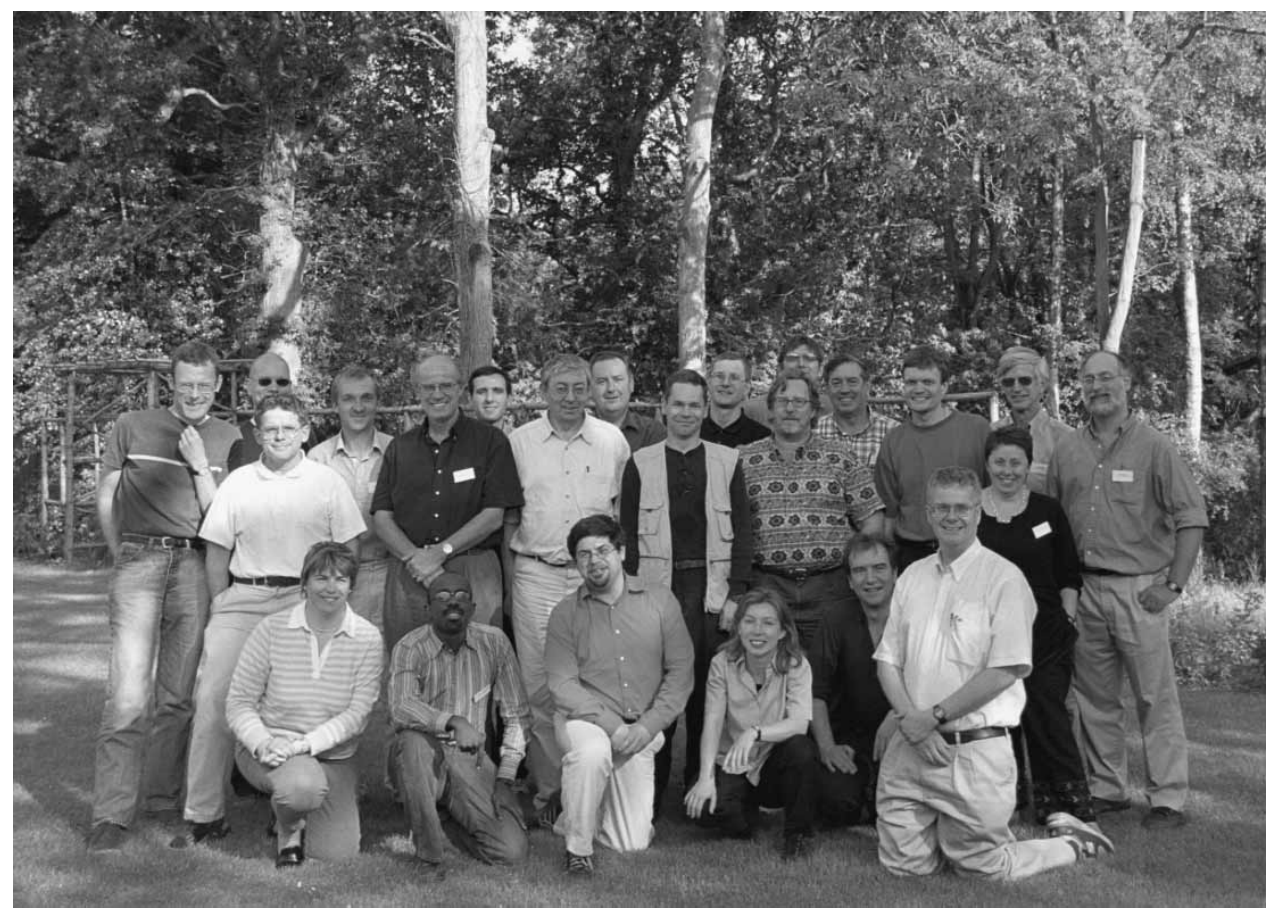

Participants of the Mathematical Virology Workshop, June 2004, Oxford, UK. 

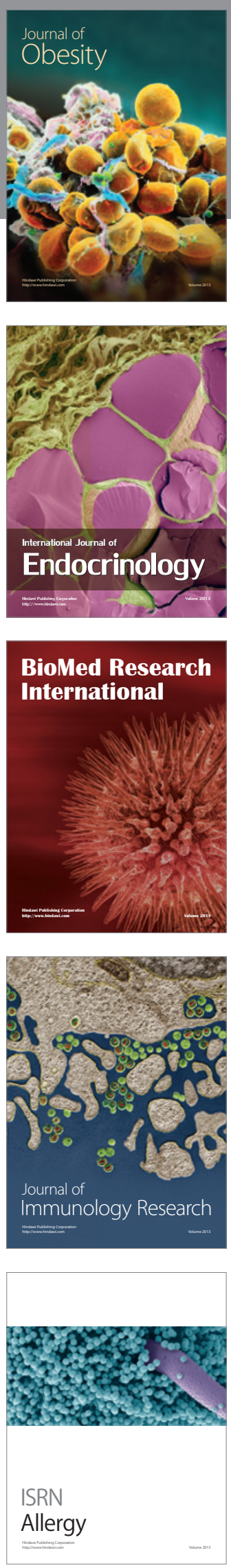
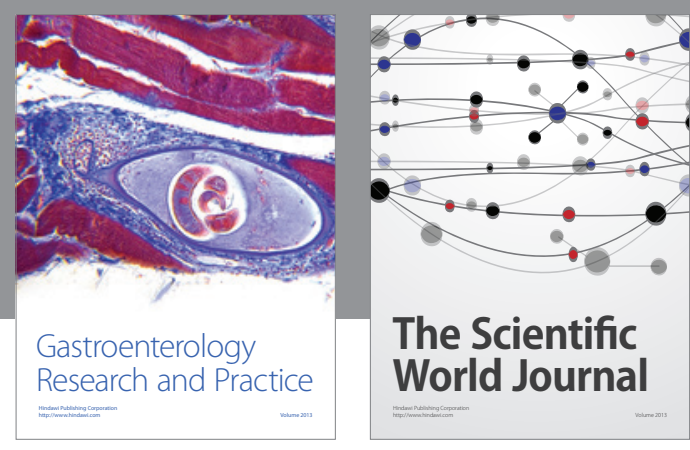

The Scientific World Journal
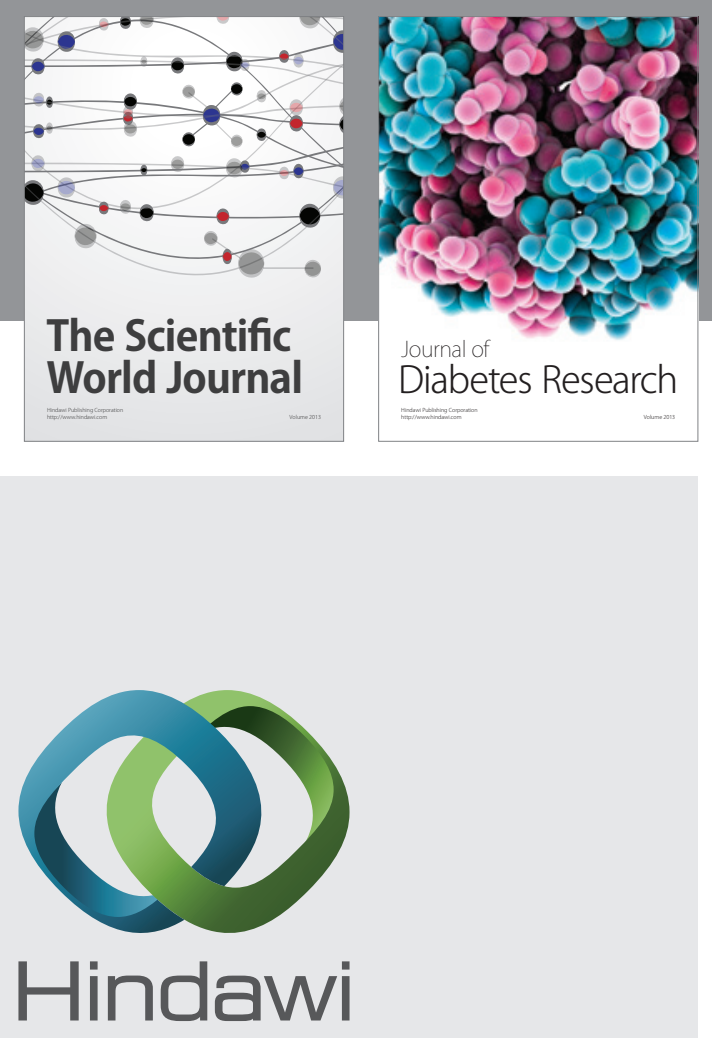

Submit your manuscripts at

http://www.hindawi.com
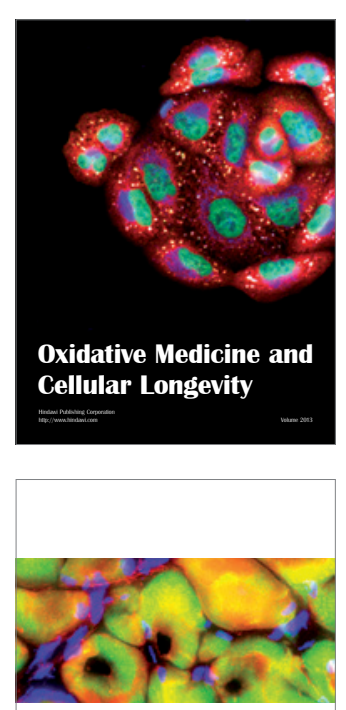

ISRN

Biomarkers
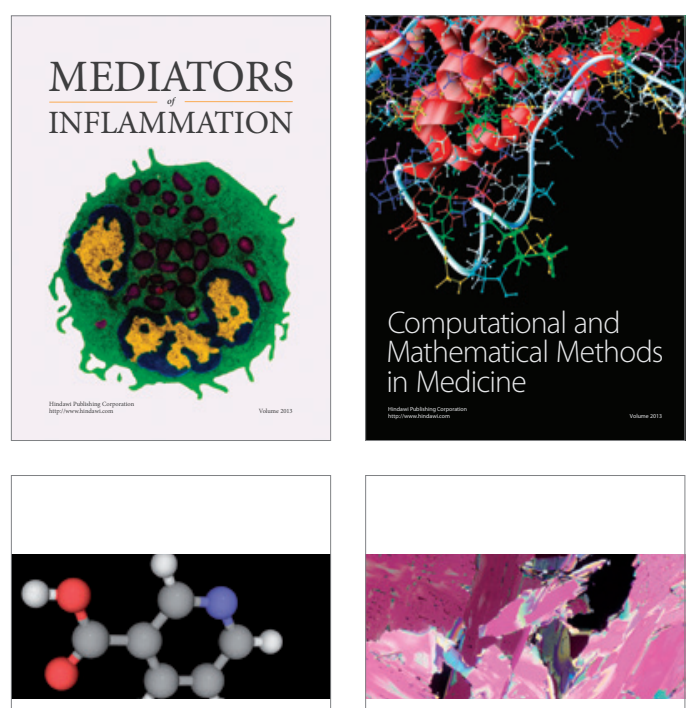

ISRN

Addiction

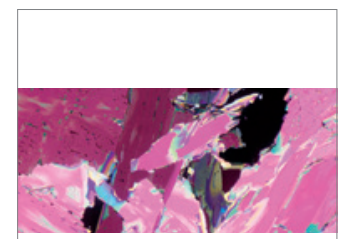

ISRN

Anesthesiology
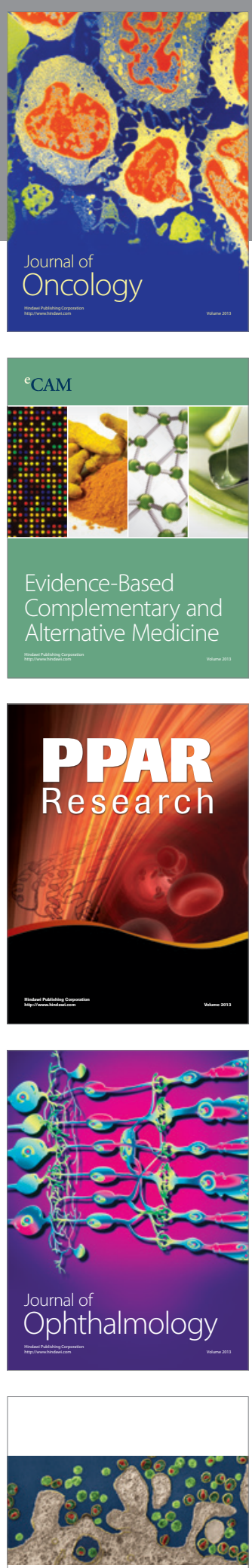

ISRN

AIDS 